\title{
Estratificação incremental com resina composta: reprodução de efeitos ópticos incisais em restauração classe IV
}

\author{
Incremental stratification with composite resin: reproduction of optical effects in \\ restoration class $I V$
}

\author{
Alana de Castro Pereira', Vitor Schweigert Bona', Juan Pablo Villabona Lopez², Sylvio Monteiro Junior ${ }^{3}$
}

Para citar este artículo: Pereira AC, Bona VS, Villabona JP, Monteiro JS. Estratificação incremental com resina composta: reprodução de efeitos ópticos incisais em restauração classe IV. Ustasalud 2018; 17: 57-66

Licencia Creative Commons \begin{abstract}
(c) (1) (\$) lo tanto, los lectores pueden acceder libremente a los artículos en su formato .pdf, igualmente podrán descargarlos y difundirlos; sin embargo no podrán modificarlos o alterarlos, adicionalmente se debe reconocer la autoría de las personas que figuran en las publicaciones, pero estas no podrán ser comercializadas.
\end{abstract}

\section{RESUMO}

O presente artigo tem como objetivo abordar o protocolo clínico utilizado na realização de restaurações estéticas um relato de caso clínico demonstrando a técnica de estratificação incremental em resina composta para a construção dos efeitos ópticos em uma restauração do tipo Classe IV. Reproduzir as características dentais presentes no terço incisal de incisivos centrais superiores pode ser um desafio estético para o odontólogo. O profissional necessita ter o conhecimento das técnicas de inserção das diferentes camadas de resina visando garantir o mimetismo óptico dental. Além disso há uma vasta gama de compósitos que possuem diferentes graus de opacidade, croma, saturação e efeito opalescente, que aliados ao treinamento do operador, visam garantir o sucesso clínico na reprodução de tais características dentais. O resultado dependerá da criteriosa sequência de passos que envolve desde o diagnóstico até as etapas de acabamento e polimento.

Palavras-chave: Restauração estética, estratificação incremental, resina composta.

\section{ABSTRACT}

The aim of this article is to discuss the clinical protocol used in the accomplishment of aesthetic restorations, with a clinical case report demonstrating the technique of incremental stratification in composite resin for the construction of optical effects in a Class IV restoration. Reproducing the dental characteristics present in the incisal third of the upper central incisors can be an aesthetic challenge for the dentist. The professional needs to have knowledge of the insertion techniques of the different resin layers in order to guarantee dental optical mimicry. In addition there is a wide range of composites that have different degrees of opacity, chroma, saturation and opalescent effect, which, together with operator training, aim to guarantee clinical success in reproducing such dental characteristics. The result will depend on the judicious sequence of steps involved from the diagnosis to the finishing and polishing steps.

Keywords: Aesthetic restoration, incremental stratification, composite resin.
'Mestre e Doutorando(a) em Odontologia com ênfase em Dentística pela Universidade Federal de Santa Catarina, Brasil

${ }^{2}$ Graduação em Odontologia pela Universidad Santo Tomás Colômbia

${ }^{3}$ Professor titular do Programa de Pós-graduação em Odontologia da Universidade Federal de Santa Catarina, Brasil

Autor responsável por correspondência:

Alana de Castro Pereira alanaxpereira@hotmail.com
29 de octubre 2018. 


\section{INTRODUÇÃO}

Restaurações diretas com resina composta em dentes com terço incisal translúcido têm sido um desafio para o dia-a-dia clínico do odontólogo. Apesar de suscitar grande interesse nos profissionais, em muitas situações o resultado final obtido numa restauração deste tipo pode não superar as expectativas do operador, visto à dificuldade da correta estratificação das diferentes camadas de compósito, que visam mimetizar à anatomia dental ${ }^{1-7}$. O sucesso clínico desse tipo de procedimento depende da seleção de materiais e técnicas que emulam o dente natural e proporcionam estabilidade a longo prazo nas características ópticas ${ }^{8,9}$.

Os compósitos vêm evoluindo ao longo dos anos no que diz respeito à optimização das suas propriedades ópticas e mecânicas, bem como ao desenvolvimento de novas técnicas ${ }^{10}$. A possibilidade de se escolher resinas que possuem elevada translucidez permite ao operador reproduzir a opalescência do bordo incisal, contudo há uma necessidade do domínio das técnicas restauradoras ${ }^{3,11}$.

Algumas propriedades são de suma importância durante a confecção de uma restauração estética anterior como cor, translucidez, opalescência e fluorescência ${ }^{12}$. Neste quesito o profissional dispõe de ampla gama de materiais restauradores no mercado que atendem essas expectativas. Este atual arsenal é de alta qualidade e, quando usados apropriadamente, têm provado excelentes resultados clínicos de longevidade adequada ${ }^{4,10,13}$. Para a confecção de restaurações anteriores, o que inclui as cavidades do tipo classe $\mathrm{IV}$, as resinas compostas são uma excelente escolha e apresentam um bom desempenho clínico com taxas anuais de falha significativamente baixas ${ }^{14,15}$.

Durante a execução de uma restauração estética, além da escolha dos compósitos, um requisito importante é o conhecimento da anatomia e do comportamento dos tecidos dentais no que diz respeito à interação com a luz. No terço cervical a predominância da dentina expressa uma área mais saturada enquanto que no terço médio percebe-se com mais precisão o valor. O terço incisal demonstra uma zona de alta translucidez, exibida principalmente em dentes mais jovens, com a presença de mamelões, halo opalescente e halo opaco ${ }^{3}$.
$\mathrm{Na}$ tentativa de reproduzir tais características, os erros clínicos frequentes na confecção de restaurações anteriores baseiam-se não somente na eleição inapropriada dos compósitos, mas também na inserção de espessuras incorretas o que pode resultar em camadas muito esbranquiçadas ou acinzentadas ${ }^{16,17,18}$.

O presente artigo propõe descrever os passos mais importantes a serem considerados durante o planejamento e confecção de uma restauração estética do tipo classe IV, com base na literatura e exemplificando o protocolo clínico com um relato de caso.

\section{TÉCNICA DE ESTRATIFICAÇÃO INCRE- MENTAL EM RESTAURAÇÕES COM COM- PÓSITOS DO TIPO CLASSE IV}

A compreensão da técnica de estratificação incremental em restaurações anteriores deve incluir alguns fatores como a interrelação entre as propriedades ópticas da luz e os diferentes materiais restauradores, criando assim, a ilusão da estética natural. Para tanto, o cirurgião-dentista deve estar consciente da morfologia e anatomia dos tecidos dentários, das propriedades das resinas compostas de escolha e principalmente da interação da luz com a restauração. Além disso é imprescindível uma correta seleção de saturação da cor como também determinar a correta espessura da proporção esmalte/dentina, levando-se em consideração a quantidade e a posição dos incrementos ${ }^{2,3,7,9,12,19-23}$.

Um bom resultado estético dependerá da criteriosa sequência de passos que envolve desde o diagnóstico até as etapas de acabamento e polimento. É importante determinar qual protocolo será utilizado em cada caso, porém de uma forma geral os seguintes quesitos devem ser considerados:

Conhecimento das propriedades do compósito de escolha.

Estudo das características ópticas do dente homólogo, levando-se em consideração a observação clínica e as fotografias como auxiliares.

Eleição das cores das resinas, das diferentes opacidades e oportunidade de testá-las a partir de um ensaio restaurador. 
Guia de referência para a confecção da cunha palatina em resina composta, registrada em silicone de adição no ensaio restaurador ou enceramento diagnóstico.

Técnica de estratificação incremental determinando a quantidade e posição dos incrementos, a espessura e proporção correta de acordo com a anatomia do dente homólogo estudado.

Etapas de acabamento, texturização e polimento final seguindo uma sequência lógica e propiciando uma superfície de interação com a luz semelhante àquela encontrada nos dentes naturais.

\section{Sequência clínica}

O paciente do sexo masculino, com 25 anos de idade, apresentou-se à clínica de Pós-graduação em Odontologia da Universidade Federal de Santa Catarina situada no Brasil queixando-se de insatisfação quanto ao seu sorriso. Durante a anamnese o paciente relatou um episódio de trauma na infância que resultou em fraturas nos dentes anteriores e que as restaurações teriam sido realizadas há mais de dez anos. Ao exame clínico observou-se duas restaurações de resina composta do tipo classe IV nos elementos 11 e 12 com forma, coloração e textura superficial insatisfatórias (Figura 1).

Foi observado também uma trinca horizontal no dente 11 abrangendo desde a distal até a mesial, contudo os dentes encontravam-se com vitalidade pulpar. Não foram observados sinais clínicos de sangramento decorrente de gengivite e/ou periodontite. Ao exame radiográfico não foram detectadas presença de lesões periapicais.

\section{Estudo e planejamento do caso}

De acordo com as necessidades do paciente, o planejamento do caso consistiu primeiramente na realização de um clareamento dental de consultório com a aplicação de peróxido de hidrogênio a 35 \% (Pola Office, SDI Limited, Bayswater, Victoria, Australia) combinado à técnica de clareamento caseiro supervisionado com peróxido de carbamida a 10\% (Power Bleaching, BM4, Brasil Materiais e Instrumentais Ltda, Palhoça, SC, Brasil). Além das instruções de uso, o paciente foi alertado quanto a impossibilidade de ação clareadora na restauração antiga, o que poderia gerar um maior contraste de cor entre dente e compósito. Alcançado o sucesso no tratamento clareador (Figura 2), foi aguardado um período de quinze dias para a liberação total do oxigênio reativo residual decorrente do clareamento. A literatura relata que esses íons interferem negativamente no processo de adesão ${ }^{24}$.

Para o planejamento da restauração classe IV foi necessária a observação dos efeitos ópticos presentes no dente homólogo com o auxílio de fotografias em macro. Com isso é possível identificar as zonas de maior croma, maior translucidez, zonas de opalescência e contra-opalescência. Além disso, a fotografia pode ser editada para uma melhor visualização dos efeitos ópticos (Figura 3). Os valores de contraste e saturação, quando exacerbados, exibem com mais nitidez as características do dente natural. Reproduz-se com mais fidelidade o que melhor se conhece.A partir deste estudo pôde-se lançar mão dos possíveis compósitos que seriam utilizados para mimetizar os efeitos ópticos. No caso foram eleitas resinas compostas nanohíbridas (IPS Empress Direct, Ivoclar Vivadent, Schaan, Lietchtenstein) de dentina na cor B1 (Dentin B1), de esmalte na cor B1 (Enamel B1), de efeito opalescente (Trans Opal) e de esmalte acromático (Trans 30). O croma escolhido levou em consideração o resultado final do esmalte clareado. Um ensaio restaurador foi realizado para testar se as cores escolhidas correspondiam aos efeitos ópticos do dente homólogo (Figuras 4 e 5). Após uma remoção conservadora da restauração antiga, os compósitos escolhidos foram inseridos com um pequeno ponto de adesão na face vestibular.

Esse procedimento visou dar oportunidade ao operador entender como seriam inseridas as camadas de resina. Percebeu-se que os incrementos de dentina com característica mais opaca poderiam ser levados até próximo à trinca, pois ela interferia negativamente na estética, e os incrementos de resina de efeito opalescente poderiam ser melhor explorados no terço incisal. $\mathrm{O}$ ensaio restaurador foi feito devolvendo principalmente o contorno palatal para a confecção de uma guia em silicone de adição (Express, 3M ESPE, St Paul, MN, USA) que posteriormente serviu de referência na restauração definitiva (Figura 6). 


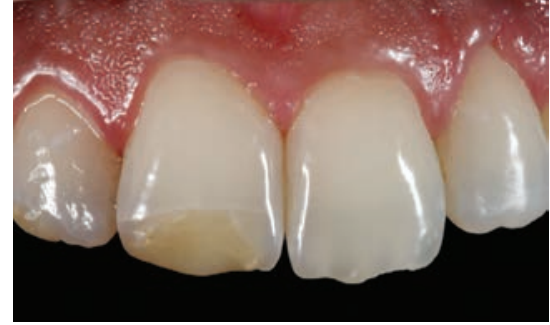

Figura 1. Situação clínica inicial.

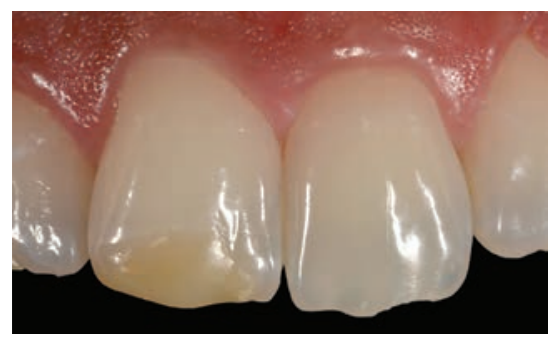

Figura 2. Situação clínica após o clareamento dental.
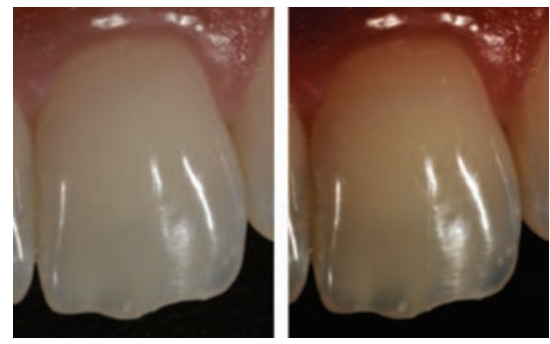

Figura 3. Alterações nos valores de contraste e saturação.
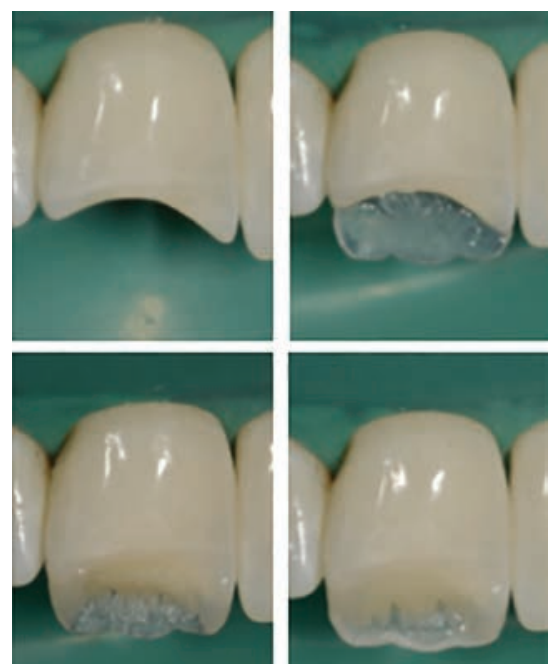

Figura 4. Sequência do ensaio restaurador.

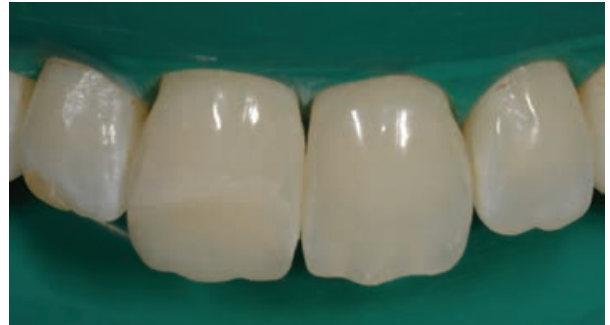

Figura 5. Ensaio restaurador finalizado.
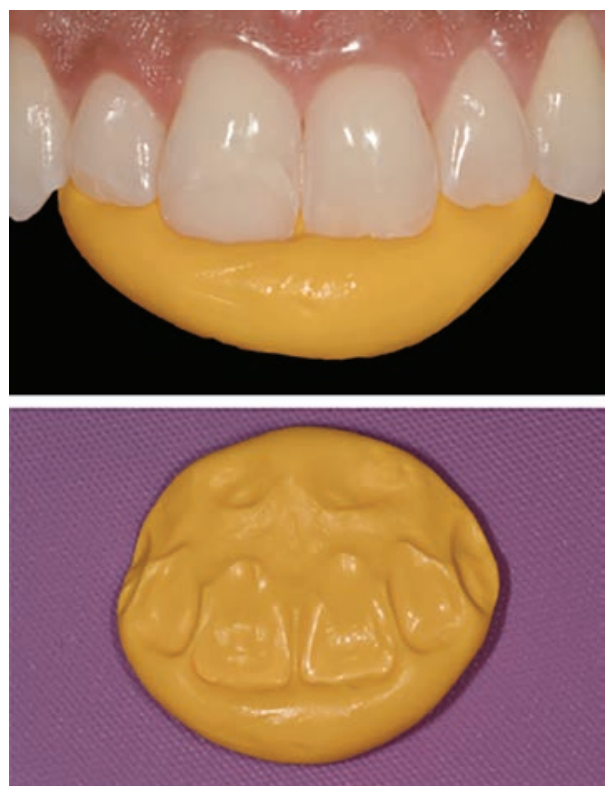

Figura 6. Confecção da guia de silicone

Em seguida os dentes 12 e 21 foram protegidos com fita de tetrapolifluoretileno (Tigre, Joinville, SC, Brasil) para a aplicação do ácido fosfórico a 37 \% (Power Etching, BM4, Brasil Materiais e Instrumentais Ltda, Palhoça, SC, Brasil) 3mm além da margem de esmalte durante 30 segundos e na dentina por 15 segundos (Figura 8 A e B).

Após abundante lavagem com jatos de água por 60 segundos e secagem do esmalte com proteção da dentina, foi aplicado o sistema adesivo (Single Bond, 3M ESPE, St. Paul, MN, USA) e fotopolimerizado de acordo com as recomendações do fabricante (Figura 9).

Um incremento de resina de alta translucidez Trans 30 (IPS Empress Direct, Ivoclar Vivadent, Schaan, Lietchtenstein) foi levado à guia de silicone cuidadosamente, para evitar a incorporação de bolhas (Figura 9). 


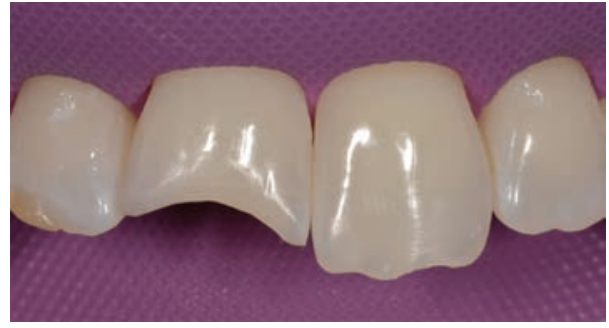

Figura 7. Preparo do dente 11 sob isolamento absoluto.
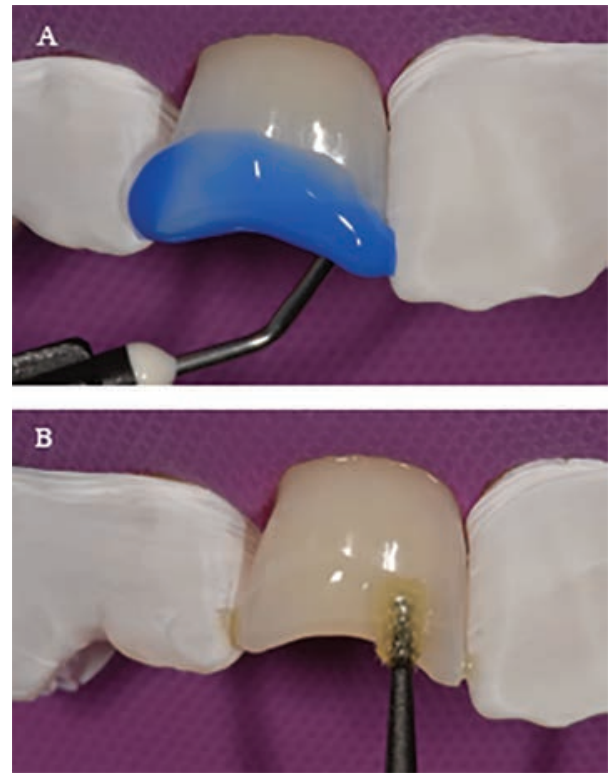

Figura 8. A. Aplicação do ácido fosfórico a 37 \%. B. Aplicação do sistema adesivo.

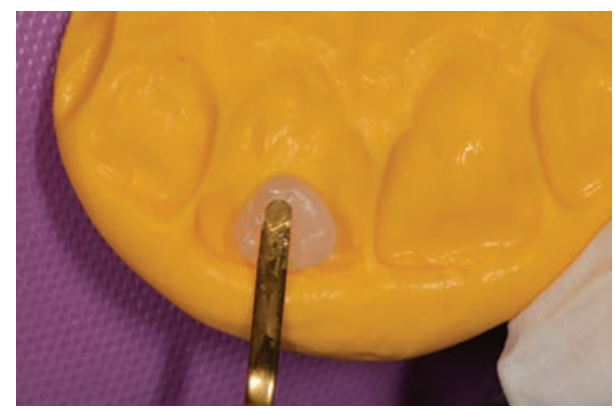

Figura 9. Inserção do compósito na guia de silicone.

A guia, então, foi levada à superfície palatal dos dentes anteriores, servindo de referência para a confecção da cunha palatina em resina composta, seguindo o contorno dado previamente com o ensaio restaurador (Figuras $10 \mathrm{~A}-\mathrm{C}$ ).
Dando sequência à estratificação incremental, as paredes proximais foram construídas com resina de esmalte cromático na EB1 (IPS Empress Direct, Ivoclar Vivadent, Schaan, Lietchtenstein) em incrementos de aproximadamente $1 \mathrm{~mm}$ de espessura (Figura $10 \mathrm{D})$.
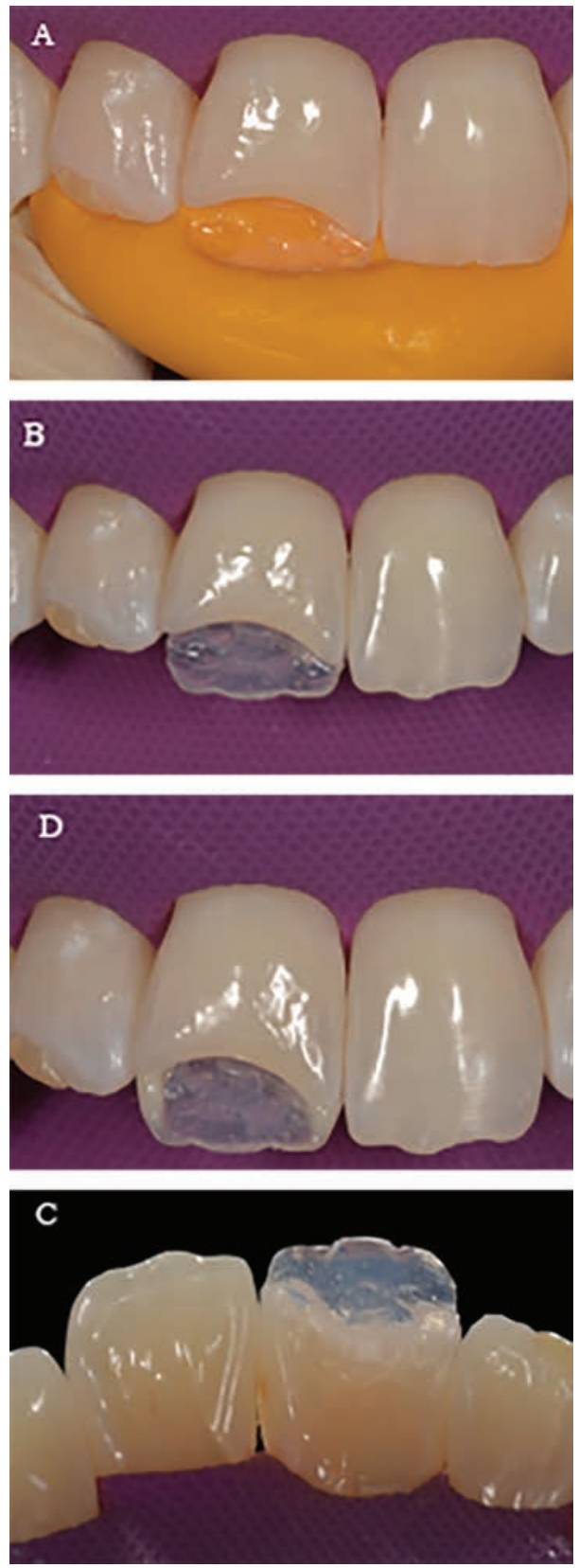

Figura 10. A y B. Construção da face palatina. C. Visualização do incremento fotopolimerizado por face palatal. D. Construção das paredes proximais com compósitos de esmalte. 
Um delgado incremento de resina de baixa translucidez DB1 (IPS Empress Direct, Ivoclar Vivadent, Schaan, Lietchtenstein) foi utilizado para a construção do halo opaco incisal (Figura 11. A e B).

Em seguida outro incremento de resina DB1 (IPS Empress Direct, Ivoclar Vivadent, Schaan, Lietchtenstein) foi inserido até a próximo à margem de esmalte reproduzindo os mamelões dentinários, em incrementos de aproximadamente $2 \mathrm{~mm}$ de espessura cada um (Figura $11 \mathrm{C}$ ). A reprodução dos mamelões seguiu o estudo realizado anteriormente com o auxílio das fotografias em macro do dente homólogo.
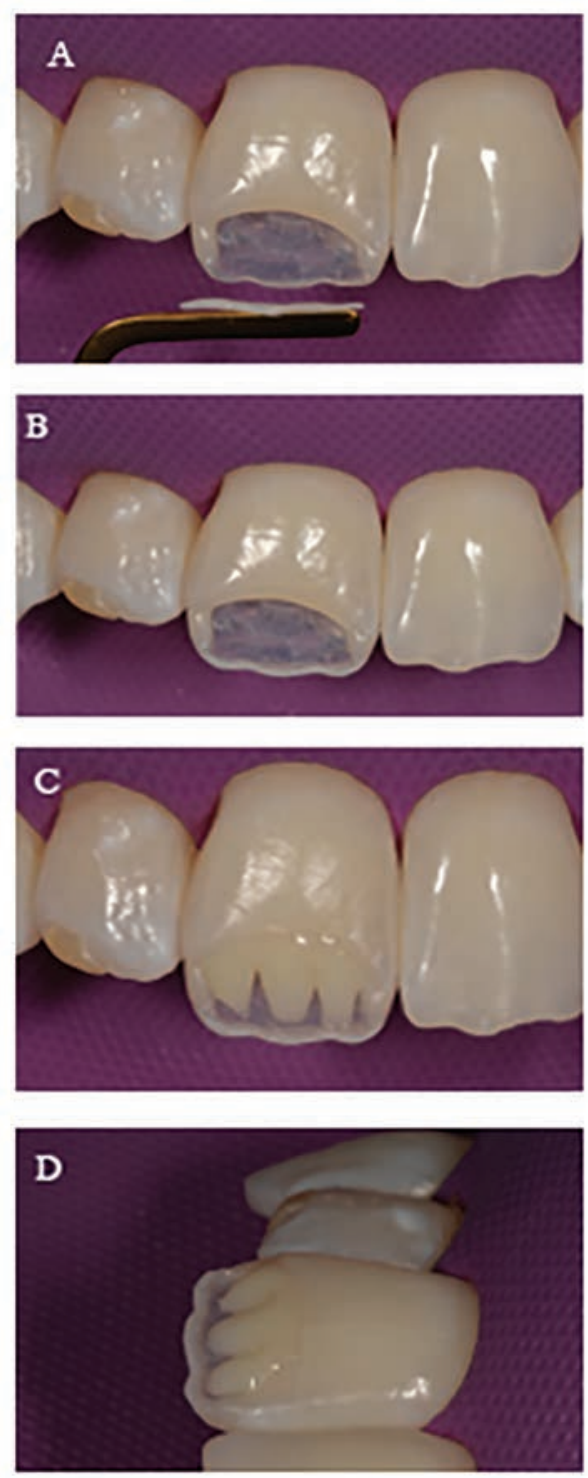

Figura 11. A-B. Construção do halo opaco com resina de dentina. C. Caracterização dos mamelos dentinários com resina de dentina. D. Vista proximal dos mamelos dentinários construídos em resina composta E-F. Inserção do incremento de resina opalescente. G. Vista palatal do efeito opalescente no bordo incisal. H. Inserção da camada de esmalte.

As massas de dentina respeitaram a inclinação dental e o espaço para os incrementos de resina subsequentes. Observa- se que este incremento deve avançar ligeiramente sobre o inicio da margem para que haja um mascaramento da linha de transição compósito/ dente (Figura $11 \mathrm{D})$.

No espaço entre o halo opaco incisal e os mamelões de dentina, de aproximadamente $2 \mathrm{~mm}$ foi inserido um incremento de resina de efeito opalescente com característica azulada, TBlue (Opallis FGM Produtos Odontológicos, Joinville, Santa Catarina). O cuidado neste incremento foi com a não incorporação de bolhas (Figuras $11 \mathrm{E}$ e F).
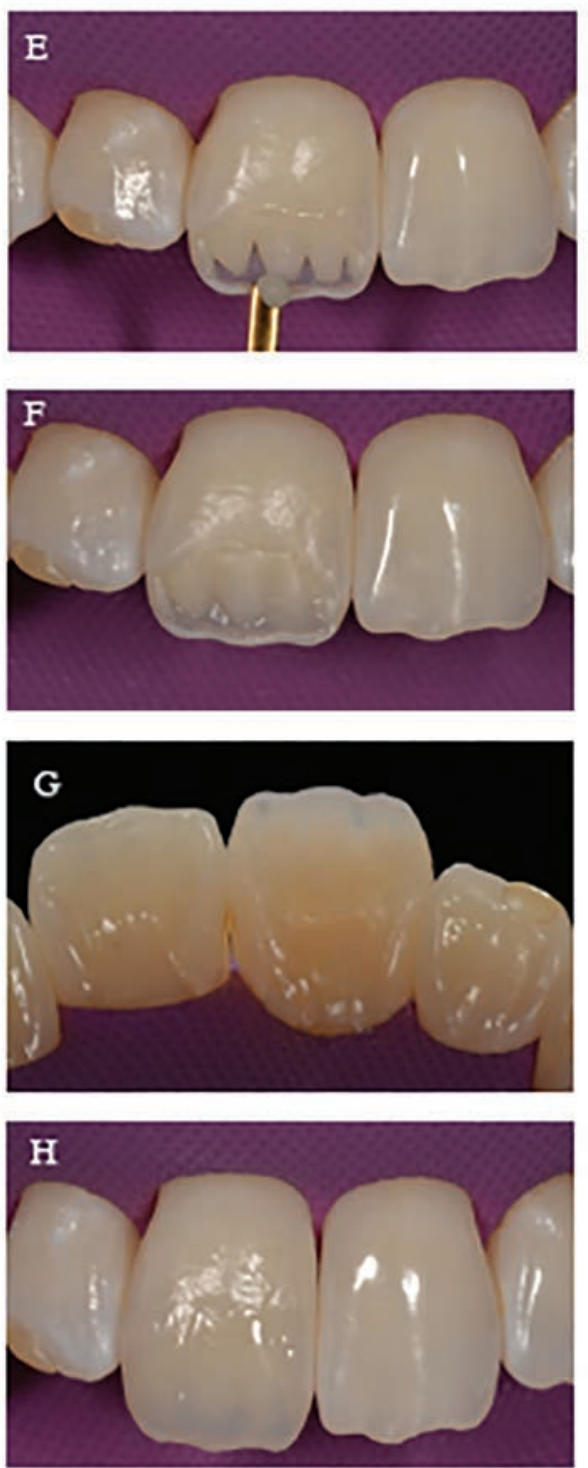
Finalizando a restauração, para estratificar a superfície vestibular um incremento de resina de esmalte cromático EB1 foi inserido devolvendo o contorno das cristas proximais. Com o auxílio de espátulas e pincéis próprios para resina composta, a camada de resina de esmalte foi levada um pouco além da margem, conferindo anatomia.

Com a conclusão da estratificação incremental as superfícies dentais encontravam-se desidratadas por conta do isolamento da umidade, sendo impossível a conferência de cor na mesma consulta (Figura $11 \mathrm{H}$ ). Imediatamente após a remoção do isolamento absoluto foram realizados os ajustes oclusais e remoção dos excessos mais grosseiros.

Após um período de $48 \mathrm{~h}$ o paciente retornou com os dentes reidratados e pôde-se observar com mais fidelidade a compatibilidade de cor dos incrementos de resina escolhidos para a confecção da restauração classe IV (Figura $12 \mathrm{~A}$ ).

Seguiu-se, portanto, os procedimentos de texturização e polimento final. Primeiramente delimitou-se a área plana com o auxílio de discos abrasivos (Dia- mond Pro FGM Produtos Odontológicos, Joinville, Santa Catarina), (Figura 12 B) e em seguida os sulcos verticais foram reproduzidos com uma ponta diamantada da série F no 2135 (KG Sorensen, São Paulo, Brasil), inclinada horizontalmente (Figura $12 \mathrm{C}$ ).

Os contornos incisais com aspecto de "flor de lis" presentes no dente homólogo também foi reproduzido naincisal da restauração com discos de maior abrasividade (Figura $12 \mathrm{D})$.

Borrachas e discos abrasivos (Super Snap Xtreme, Shofu Inc., Kyoto, Japan) foram utilizados na superfície palatal (Figura 12 E) e também para suavizar as texturas realizadas na superfície vestibular com as pontas diamantadas da série F e FF (KG Sorensen, São Paulo, Brasil).

Com a técnica de estratificação incremental, as dimensões são atentamente reconstituídas com as camadas de compósitos e durante a fase de acabamento e polimento as inclinações cérvico-incisal e mesio-distal devem ser respeitadas, garantindo uma anatomia semelhante ao dente homólogo (Figura $12 \mathrm{~F}$ ).
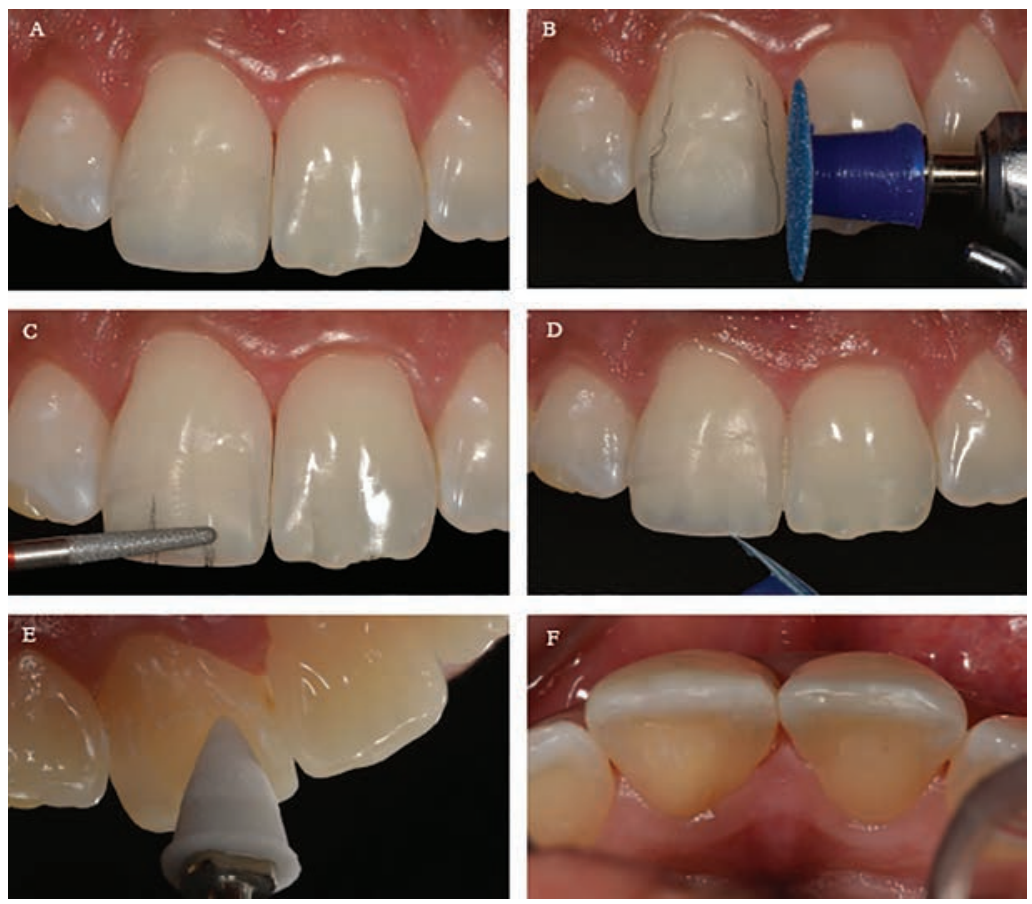

Figura 12 A. Vista frontal da restauração após 48 horas. B. Delimitação da área plana.C. Texturização dos sulcos verticaisD. Confecção do aspecto "flor de lis" no bordo incisal. E. Uso de borrachas abrasivas. F. Vista incisal conferindo as dimensões com o dente hígido homólogo. 
Além disso, as etapas de texturização e polimento devem conferir à face vestibular uma superfície de reflexão de luz de forma dinâmica (Figuras 13 A e B).
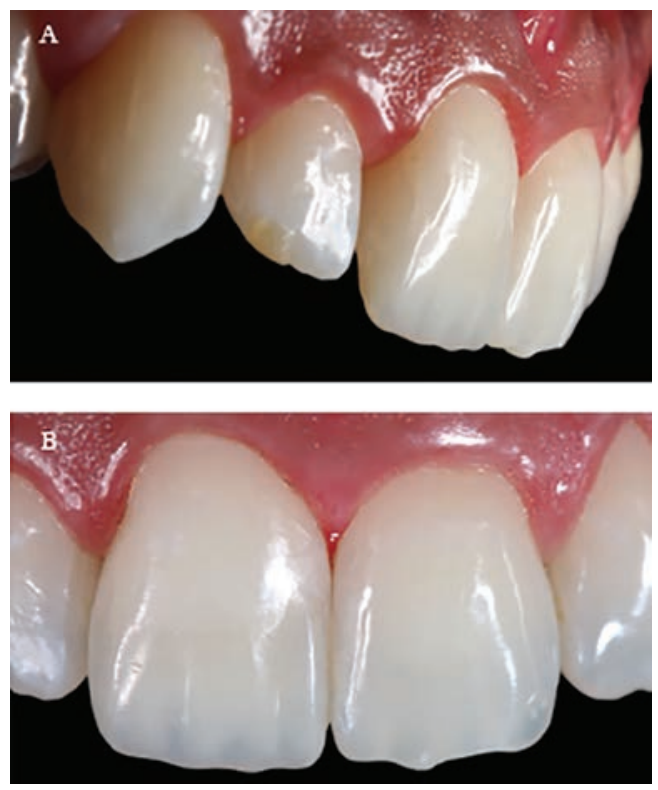

Figura 13. A. Vista proximal conferindo a texturização da face vestibular e sua interação com a luz. B. Vista frontal do caso finalizado.
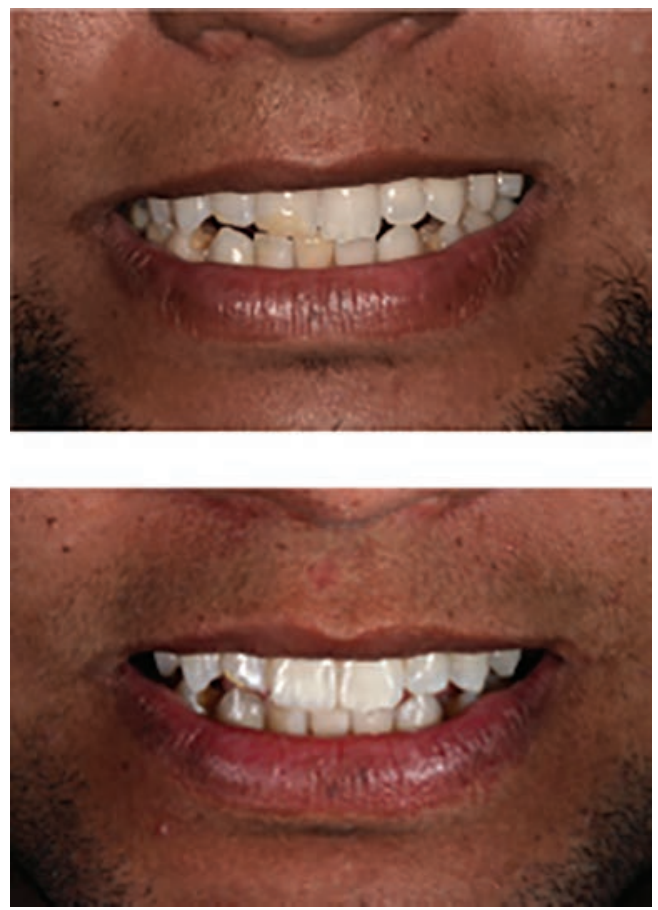

Figura 14. Aspecto inicial e final do caso clínico após tratamento clareador e restauração classe IV seguindo a técnica de estratificação incremental.

\section{DISCUSSÃO}

Baratieri, Araujo e Monteiro $\mathrm{Jr}^{8}$ descreveram os aspectos essenciais para entender e reproduzir a cor dos dentes naturais com o uso de resina composta. Dentre diversas características, a fluorescência, opalescência e especialmente a contra-opalescência foram discutidas, sendo as principais responsáveis pelos efeitos ópticos incisais, como o aspecto alaranjado nos mamelões dentinários em dentes anteriores. $\mathrm{O}$ entendimento destes quesitos foi determinante para a realização e o sucesso clínico alcançado ao final do tratamento restaurador relatado no presente artigo.

O planejamento do caso clínico incluiu a restauração em resina composta por ser uma alternativa conservadora e eficaz, visto a ampla gama de materiais à disposição para a reprodução das características ópticas aliado à boas propriedades mecânicas, garantindo o sucesso do tratamento. Na revisão sistemática realizada por Demarco et $a^{14}$, foi observado que as restaurações anteriores possuem uma boa longevidade clínica, com taxas anuais de falhas variando entre 0 e $4,1 \%$. As falhas relacionadas à qualidade estética como cor, forma anatômica e manchamento superficial foram as mais observadas. Concordando com os autores, no presente caso clínico optou-se pela completa substituição da restauração antiga por razões semelhantes.

Optou-se pela utilização de compósitos nanohíbridos pois esses materiais são geralmente considerados universais, com possibilidade de uso na maioria das aplicações anteriores e posteriores, levando-se em consideração a sua combinação de resistência e alto grau de polimento. Segundo Ferracane ${ }^{10}$ não existe um material ideal, contudo, as resinas compostas existentes no mercado são de alta qualidade e, quando usados com as técnicas apropriadas, têm provado excelentes resultados clínicos de longevidade adequada.

A técnica eleita para a construção da restauração classe IV foi a da estratificação incremental, visando devolver forma e cor de acordo com os tecidos dentais. Dessa forma os incrementos de resina são inseridos emulando as camadas de esmalte e dentina em proporções semelhantes, assim, espera-se que a interação do compósito com a luz seja a mais próxima possível da interação encontrada nos dentes naturais. O planejamento do caso corroborou com os achados de El- 
gendy et $a l^{9}$, onde em seu estudo foram investigadas três diferentes técnicas de restauração, comparando os resultados com os dentes naturais. No primeiro grupo a restauração foi construída incrementalmente apenas com resina de corpo na cor B1; no segundo grupo foram eleitas uma resina de dentina $\mathrm{A} 2$ e esmalte $\mathrm{B} 1$; no terceiro grupo a restauração foi construída com incrementos de dentina A2 seguido e resina Transparente e esmalte B1. A interação da luz foi medida com três tipos de lasers. Os resultados do estudo mostraram que a restauração monocromática não pôde replicar completamente a orientação complexa da cor encontrada no tecido dental natural sendo necessária a seleção de várias cores, distribuídos incrementalmente.

Além de auxiliar na reprodução das camadas dentais, a técnica de estratificação incremental, segundo Betrisey et $\mathrm{al}^{6} \mathrm{e}^{\mathrm{C}}$ Chandrasekhar et $\mathrm{al}^{23}$, também é uma ferramenta fundamental para o operador lidar com a tensão de contração da polimerização, fornecendo uma fotopolimerização adequada em cada incremento.

O estudo realizado por Arimoto et $a l^{4}$ investigou as características de translucidez, opalescência e transmissão luminosa de resinas compostas de diferentes espessuras. Os autores concluíram que nas espessuras de $0,5 \mathrm{~mm}$, a translucidez e a opalescência dos compósitos resinosos apresentaram correlação significativa com a propriedade de transmissão difusa, porém quando maiores de $1,0 \mathrm{~mm}$ a translucência diminuiu significativamente e a opalescência aumentou significativamente. Esses achados estão de acordo com as características ópticas observadas no ensaio restaurador do presente artigo (Figura 5), onde foram inseridos incrementos mais espessos de resina de esmalte, influenciando negativamente na reprodução das características ópticas tão presente na porção incisal do dente homólogo. Sidhu et $a l^{17}$ observaram que em cavidades grandes classe III ou IV, materiais translúcidos podem fornecer correspondências de cores relativamente fracas ou uma tonalidade acinzentada pois são afetados pela escuridão da cavidade oral. Em tais situações, têm sido utilizados compósitos resinosos de cor opaca, em espessuras maiores. No caso clínico relatado, as espessuras dos incrementos foram corrigidas na restauração definitiva, promovendo o sucesso da restauração final (Figura 14).

\section{CONCLUSÕES}

As restaurações em resina composta do tipo classe IV permanecem sendo um grande desafio estético ao odontólogo, mesmo com a disponibilidade ostensiva de compósitos capazes de mimetizar os tecidos dentais. Essa ampla gama de materiais força ao operador atentar-se às propriedades ópticas e aos passos de inserção para garantir o sucesso estético. O protocolo de estratificação incremental deve ser a técnica de eleição para este tipo de procedimento. Porém, para resultar em naturalidade, há a necessidade de um conhecimento prévio sobre os comportamentos de luz e cor, bem como sua interação com a superfície dental. Apesar da importância de ser realizar um protocolo clínico como o descrito, o presente artigo conclui que as situações devem sempre ser analisadas individualmente e planejadas de acordo com a necessidade de cada paciente.

\section{REFERÊNCIAS}

1. Dietschi D. Layering concepts in anterior composite restorations. J Adhes Dent. 2001; 3(1): 71-80. PMID: 11317387.

2. Correia A, Oliveira MA, Silva MJ. Conceitos de Estratificação nas Restaurações de Dentes Anteriores com Resinas Compostas. Revista Portuguesa de Estomatologia, Medicina Dentária e Cirurgia Maxilofacial 2005; 46(3): 171-178.

3. Muniz L, Rhem M. Restauração de borda incisal translúcida: um desafio para a Odontologia Estética. Relato de caso clínico. R Dental Press Estét 2006; 3(1): 39-48.

4. Arimoto A, Nakajima M, Hosaka K, Nishimura K, Ikeda M, Foxton RM, Tagami J. Translucency, opalescence and light transmission characteristics of light-cured resin composites. Dent Mater. 2010; 26(11): 1090-7. DOI: 10.1016/j.dental.2010.07.009.

5. Naeimi Akbar H, Moharamzadeh K, Wood DJ, Van Noort R. Relationship between Color and Translucency of Multishaded Dental Composite Resins. Int J Dent. 2012; 2012:708032. DOI: 10.1155/2012/708032.

6. Betrisey E, Krejci I, Di Bella E, Ardu S. The influence of stratification on color and appearance of resin composites. Odontology. 2016; 104(2): 176-83. doi: 10.1007 / s10266-015-0197-2. 
7. Dietschi D, Fahl N Jr. Shading concepts and layering techniques to master direct anterior composite restorations: an update. Br Dent J. 2016; 221 (12): 765-771. DOI: 10.1038/sj.bdj.2016.944.

8. Baratieri LN, Araujo E, Monteiro S Jr. Color in natural teeth and direct resin composite restorations: essential aspects. Eur J Esthet Dent. 2007; 2(2): 172-86. PubMed PMID: 19655564.

9. Elgendy H, Maia RR, Skiff F, Denehy G, Qian F. Comparison of light propagation in dental tissues and nano-filled resin-based composite. Clin Oral Investig. 2018. DOI: 10.1007 / s00784-018-2451-9.

10. Ferracane JL. Resin composite-state of the art. Dent Mater. 2011;27(1):29-38. DOI: 10.1016/j.dental.2010.10.020.

11. Masioli MA, Vimercati BM, Peixoto LM, et al. Preparo e Restauração Classe IV em Resina Composta. Em: Masioli MA, et al. eds. Odontologia Restauradora de A a Z. $1^{\text {a }}$ ed. Florianópolis, Editora Ponto; 2012: p 240-249.

12. Baratieri LN, Monteiro Jr S, de Melo TS, et al. Preparo e Restauração de Classe IV com compósito. Em: Baratieri LN, et al. eds. Odontologia Restauradora - Fundamentos e Técnicas. 1ª ed. São Paulo, Santos; 2010: p 203-239.

13. Bispo, LB. Resina composta nanoparticulada: há superioridade no seu emprego? Revista Dentística on line - ano 9, número 19, 2010. ISSN 1518-4889. URL disponível em: http://www.ufsm.br/dentisticaonline.

14. Demarco FF, Collares K, Coelho-de-Souza FH, Correa MB, Cenci MS, Moraes RR, Opdam NJ. Anterior composite restorations: A systematic review on long-term survival and reasons for failure. Dent Mater. 2015; 31(10): 1214-24. DOI: 10.1016/j.dental.2015.07.005.

15. Lempel E, Lovász BV, Meszarics R, Jeges S, Tóth Á, Szalma J. Direct resin composite restorations for fractured maxillary teeth and diastema closure: A 7 years retrospective evaluation of survival and influencing factors. Dent Mater. 2017; 33(4): 467-476. DOI: 10.1016/j. dental.2017.02.001.
16. Hirata R, Ampessan RL, Liu J. Reconstrução de Dentes Anteriores com Resinas Compostas - Uma Seqüência de Escolha e Aplicação de Resinas. JBC - Jornal Brasileiro de Clínica \& Estética em Odontologia 2001; 5(25): 15-25.

17. Sidhu SK, Ikeda T, Omata Y, Fujita M, Sano H. Change of color and translucency by light curing in resin composites. Oper Dent. 2006; 31(5): 598-603. PMID: 17024949.

18. Vichi A, Fraioli A, Davidson CL, Ferrari M. Influence of thickness on color in multi-layering technique. Dent Mater. 2007; 23(12): 1584-9. PMID: 17825404.

19. Milnar FJ. Selecting nanotechnology-based composites using colorimetric and visual analysis for the restoration of anterior dentition: a case report. J Esthet Restor Dent. 2004; 16(2): 89-100. PMID: 15500058.

20. Reis A, Higashi C, Loguercio AD. Re-anatomization of anterior eroded teeth by stratification with direct composite resin. J Esthet Restor Dent. 2009; 21(5): 304-16. DOI: $10.1111 /$ j.1708-8240.2009.00281.

21. Rauber GB, Bernardon JK, Vieira LCC, Baratieri LN. Evaluation of a technique for color correction in restoring anterior teeth. J Esthet Restor Dent. 2017; 29(5): 309-316. DOI: $10.1111 /$ jerd.12320.

22. Ruschel VC, Stolf SC, Shibata S, Baratieri LN. A Conservative Technique for Repairing Class IV Composite Restorations. Oper Dent. 2017; 42(1): 10-15. DOI: 10.2341/15-316-T.

23. Chandrasekhar V, Rudrapati L, Badami V, Tummala M. Incremental techniques in direct composite restoration. J Conserv Dent. 2017; 20(6): 386-391. DOI: 10.4103/JCD. JCD_157_16.

24. Monteiro R. Avaliação clínica do efeito residual no clareamento dental de consultório. Dissertação de mestrado Universidade Federal de Santa Catarina - Florianópolis, SC, 2016. 